\title{
Prevention and Management of Bleeding During Endoscopic Approaches to Skull Base Pathologies
}

\author{
James J. Evans, MD \\ Thomas Jefferson University \\ Peter S Amenta, MD \\ Tulane University School of Medicine, New Orleans LA \\ Alireza Mansouri, MD \\ University of Toronto \\ Christopher J Farrell, MD \\ Thomas Jefferson University \\ Marc R. Rosen, MD \\ Thomas Jefferson University \\ Follow this and additional works at: https://jdc.jefferson.edu/jhnj

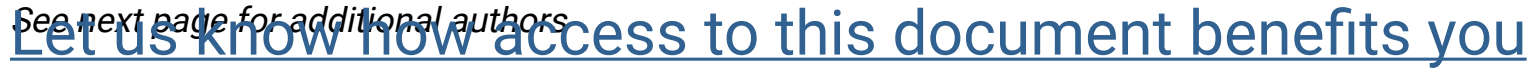

\section{Recommended Citation}

Evans, MD, James J.; Amenta, MD, Peter S; Mansouri, MD, Alireza; Farrell, MD, Christopher J; Rosen, MD, Marc R.; and Nyquist, MD, Gurston G. (2015) "Prevention and Management of Bleeding During Endoscopic Approaches to Skull Base Pathologies," JHN Journal: Vol. 10 : Iss. 2 , Article 6.

DOI: https://doi.org/10.29046/JHNJ.010.2.003

Available at: https://jdc.jefferson.edu/jhnj/vol10/iss2/6

This Article is brought to you for free and open access by the Jefferson Digital Commons. The Jefferson Digital Commons is a service of Thomas Jefferson University's Center for Teaching and Learning (CTL). The Commons is a showcase for Jefferson books and journals, peer-reviewed scholarly publications, unique historical collections from the University archives, and teaching tools. The Jefferson Digital Commons allows researchers and interested readers anywhere in the world to learn about and keep up to date with Jefferson scholarship. This article has been accepted for inclusion in JHN Journal by an authorized administrator of the Jefferson Digital Commons. For more information, please contact: JeffersonDigitalCommons@jefferson.edu. 
Prevention and Management of Bleeding During Endoscopic Approaches to Skull Base Pathologies

\section{Authors}

James J. Evans, MD; Peter S Amenta, MD; Alireza Mansouri, MD; Christopher J Farrell, MD; Marc R. Rosen, MD; and Gurston G. Nyquist, MD 


\section{Prevention and Management of Bleeding During Endoscopic Approaches to Skull Base Pathologies}

\author{
James J. Evans, MD1,2; Peter Amenta, $M D^{3}$; Alireza Mansouri, MD4; \\ Christopher J. Farrell, MD1; Marc R. Rosen, MD ${ }^{1,2}$; Gurston G. Nyquist, MD² \\ ${ }^{1}$ Department of Neurological Surgery, Thomas Jefferson University, Philadelphia, PA \\ 2Department of Otolaryngology, Thomas Jefferson University, Philadelphia, PA \\ ${ }^{3}$ Department of Neurological Surgery, Tulane University School of Medicine, New Orleans, LA \\ ${ }^{4}$ Division of Neurosurgery, Department of Surgery, University of Toronto
}

\section{Keywords \\ Anatomy, complications, endoscopic, management}

\section{Conflicts of interest}

none

\section{BACKGROUND}

The rate of serious permanent morbidity and mortality with endonasal approaches has declined secondary to increased knowledge of the pertinent anatomy, advanced neuroimaging and navigation techniques, better surgical instruments, and improved exposure and reconstruction strategies. ${ }^{1-3}$ Although rare, vascular injury remains a potentially serious complication. However, with limited systematically-collected and reported data, the exact incidence rate of vascular injuries is difficult to determine. In terms of arterial injuries, the incidence based on reported series likely ranges from $0.3 \%-9 \%$ (Table 1$),{ }^{4-11}$ with higher rates most commonly associated with chordomas and chondrosarcomas involving the clivus. Venous injury is comparatively less severe and easier to manage. As a result, there is a comparatively lower impetus to publish epidemiological data and management strategies for these injuries. The consequences of arterial injury include fatal hemorrhage, vessel occlusion or thromboembolism causing infarction, development of a pseudoaneurysm (PA), carotid-cavernous fistula (CCF), subarachnoid hemorrhage (SAH), and vasospasm. ${ }^{6,79}$ Surgical expertise and detailed knowledge of the neurovascular anatomy is critical to the avoidance and management of vascular injuries.

\section{Avoidance of vascular Injury}

Pertinent vascular anatomy

The dominant venous structures in skull base surgery are the cavernous sinuses (CS) flanking the sellar region and the basilar venous plexus on the dorsal surface of the clivus. ${ }^{12}$ The CS on either side are connected through the superior and inferior inter-cavernous sinuses; these need to be identified during drilling of the sellar bone and managed during opening of the dura. The internal carotid arteries (ICAs) coursing within the CS are the most vulnerable major arteries in the approach toward the sellar/parasellar regions. The distance between the cavernous carotids is on average $23 \mathrm{~mm}$ (Range $12-30 \mathrm{~mm}$ ), ${ }^{13-15}$ though rarely this may be as small as $4 \mathrm{~mm} .{ }^{16}$ The parasellar ICA may potentially be devoid of sphenoid bone coverage in up to $4 \%$ of the population. ${ }^{16}$ This defect may not be readily identified on preoperative imaging and its potential presence must be kept in mind during drilling of the sellar bone or using monopolar cautery in this area. In approximately $25 \%$ of the population the ICAs penetrate the medial wall of the cavernous sinus and directly contact the gland, potentially hindering the ability to develop a surgical plane during tumor dissection. ${ }^{17}$ Sellar neoplasms may displace the cavernous carotids laterally or encase the vessels altogether, increasing the risk of intraoperative hemorrhage from the ICA or its branches.

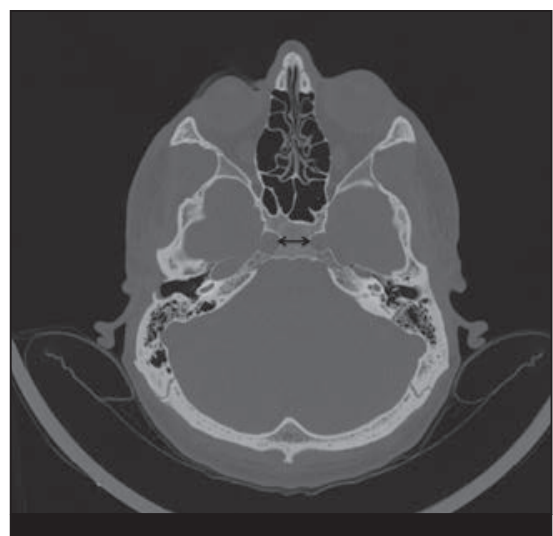

Figure 1A

Axial CT scan depicting a narrowed inter-carotid artery distance.

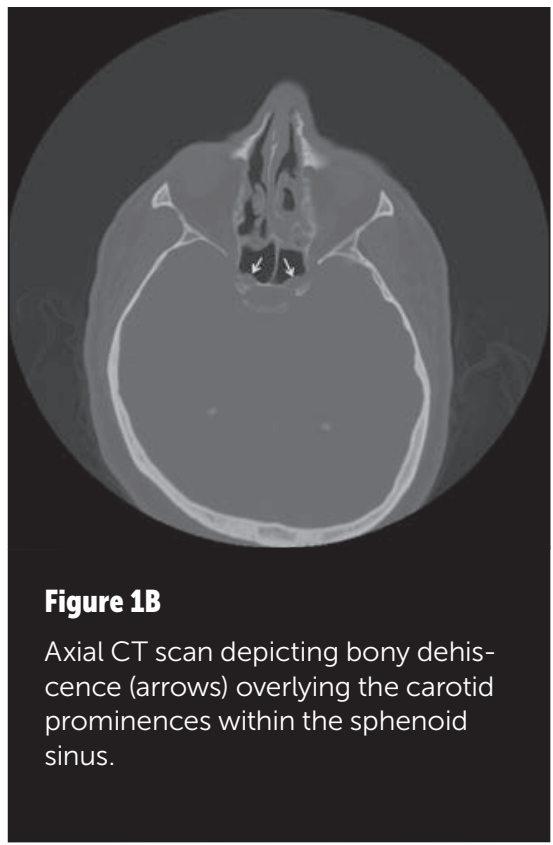




\section{Adjuncts for management of hemorrhage}

Preoperative

Imaging can help elucidate the relationship between critical neurovascular structures and the pathology. Balloon test occlusion (BTO) with neuromonitoring may be indicated in cases wherein the potential for vascular injury is high (e.g. extensive vascular encasement by the pathology). Embolization of potentially vascular tumors may be necessary to minimize intraoperative bleeding.

\section{Intraoperative}

Neuro-monitoring can be critical during the management of intraoperative vascular complications, through either indicating the neurological impact of active hemorrhage or the consequences of over-packing the site of hemorrhage during hemostasis. For example, over-packing of ICA bleeding can result in the compression of cranial nerves and even loss of anterograde blood flow, both of which can be detected with intraoperative neuromonitoring.

Using computerized surgical navigation and micro-doppler ultrasonography, location of the ICA can be confirmed prior to surgical drilling or incising the dura. In addition, the evolution of surgical tool design has contributed to minimizing the risk of vascular injury during dural opening as well; examples of these include the low-profile angled blades or scissors which direct cutting force away from the intradural surface. ${ }^{7,17}$ Intradurally, sharp extra-capsular dissection of arachnoid planes and central debulking of tumors (to avoid vessel avulsion) are important strategies. If efforts in developing a plane between the tumor and a surrounding neurovascular structure are not successful, a subtotal resection may be advisable.

\section{Management of intraoperative bleeding}

General: Regardless of the degree of bleeding, it is essential that the endoscope is not withdrawn from the surgical site. A pitfall is to over-pack the repair, which may result in carotid occlusion; neuro-monitoring should be assessed during such maneuvers to prevent irreversible ischemia.

\section{Venous}

A nuisance, but rarely life threatening. Total intravenous anesthesia does not increase intracranial pressure,

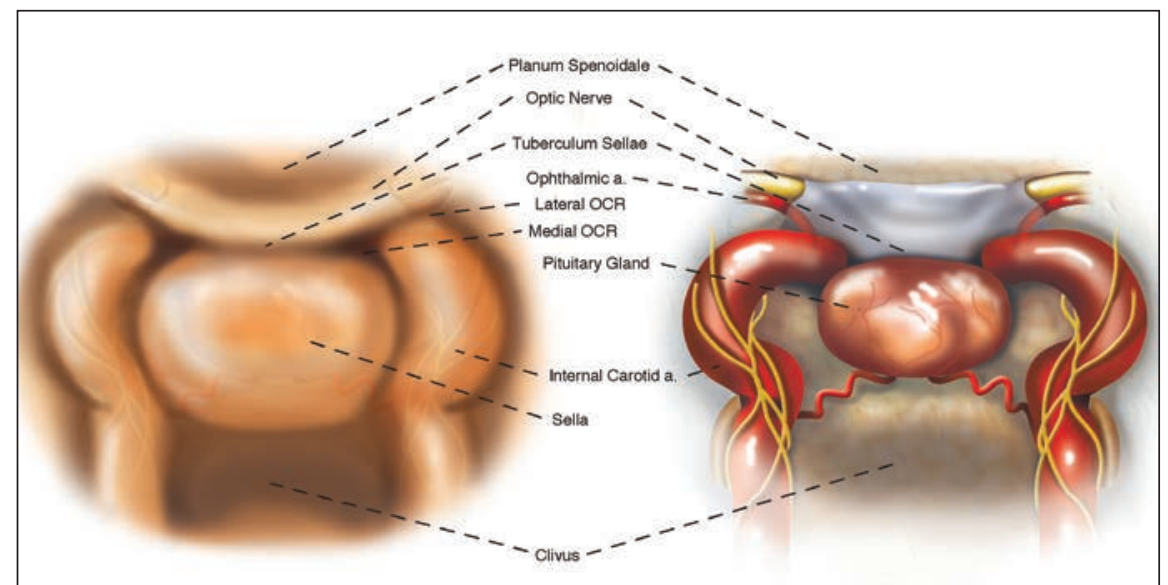

Figure 2

Although perforating branches of the ICA are small and injury to them can easily be controlled, their supply of critical structures makes the neurological consequence of sacrificing these vessels potentially dire. which is helpful for minimizing venous bleeding. Although CS bleeding can be brisk, it is usually easily managed with head elevation and gentle packing with Surgicel or FloSeal.

Arterial: The majority of ICA injuries are small and can be immediately controlled with rudimentary hemostatic methods (e.g. Gelfoam and the application of pressure with a cottonoid patty). Small lacerations can sometimes be definitively repaired with bipolar coagulation and packing with Surgicel. Larger ICA injuries during endonasal surgery are much more difficult to manage. A number of packing materials and techniques have been described, including gelfoam, fibrin glue, muslin gauze, and a crushed muscle patch. ${ }^{18-20}$ Larger lacerations can be managed with a myriad of strategies such as utilizing a two-layered muslin gauze patch that is reinforced with a fat graft or collagen sponge. ${ }^{21,7}$ Direct repair or reinforcement of the laceration may not be feasible and vessel sacrifice may be necessary. An immediate postoperative angiogram is critical to evaluate the vessel repair and to rule out early postoperative pseudoaneurysm formation. Pseudoaneurysms (PAs): The rate of postoperative ICA PA formation is highest with direct vessel injury. ${ }^{22}$ PA rupture, typically within days to weeks from diagnosis, may result in $\mathrm{SAH}, \mathrm{CCF}$, life-threatening epistaxis, or a nidus for distal thromboembolism/infarction. ${ }^{23,24}$ Even with a normal immediate postoperative angiogram, a repeat angiogram should be repeated within 7-10 days, particularly when suspicion for ICA injury is high. If open craniotomy to sacrifice the vessel is undertaken, an angiogram is necessary for assessing collateral circulation and the feasibility of an extracranial-intracranial bypass. ${ }^{21}$ Endovascular management is an alternative and includes complete ICA occlusion, coiling the PA, or vessel reconstruction with stent-assisted coiling. Coiling alone is often not successful and there is a possibility for dissection or thromboembolic events. ${ }^{25}$ Endovascular stenting may be a more feasible option. ${ }^{26}$ 


\section{CASE REPORT}

A 51-year-old male presented with a three-month history of progressive visual loss. Formal visual field testing and optical coherence tomography (OCT) revealed a chiasmal compression pattern. Contrast MRI showed a large meningioma growing along the planum sphenoidale, sella, and eroding into the sphenoid sinus (Figure 3A-D). An endoscopic endonasal approach for tumor resection was performed. Intraoperatively, a small amount of arterial bleeding was observed while aspirating tumor in the vicinity of the left ICA. The bleeding was controlled with FloSeal and the application of pressure with a cottonoid. As adequate tumor debulking had already been achieved, the procedure was stopped as a precaution due to the concern of possible ICA injury.

Immediate postoperative examination showed improved visual field exam and no other changes neurologically. MRI showed significant tumor debulking and decompression of the optic chiasm. Early in the post-operative course MRA, CTA, and an angiogram revealed normal intracranial vasculature.

\section{Learning point \#1: \\ In cavernous sinus menin- giomas, there is usually no adequate plane between the ICA and the tumor.}

Two weeks postoperatively the patient was readmitted with the acute onset of severe epistaxis, which was temporarily controlled with nasal packing. Emergent angiogram revealed a left cavernous ICA PA (Figure 4A-B). Balloon test occlusion showed no venous filling delay and the patient passed a hypotensive challenge. Several options were considered, including ICA sacrifice, bypass, and coiling of the PA. Ultimately, the PA was coiled. Although the epistaxis completely resolved, dissection and stenosis of the left ICA resulted in intermittent hemiparesis and impaired language. Imaging-confirmed left ICA dissection and embolic phenomena (Figure 5A). The decision was thus made to occlude the parent vessel with coils delivered through

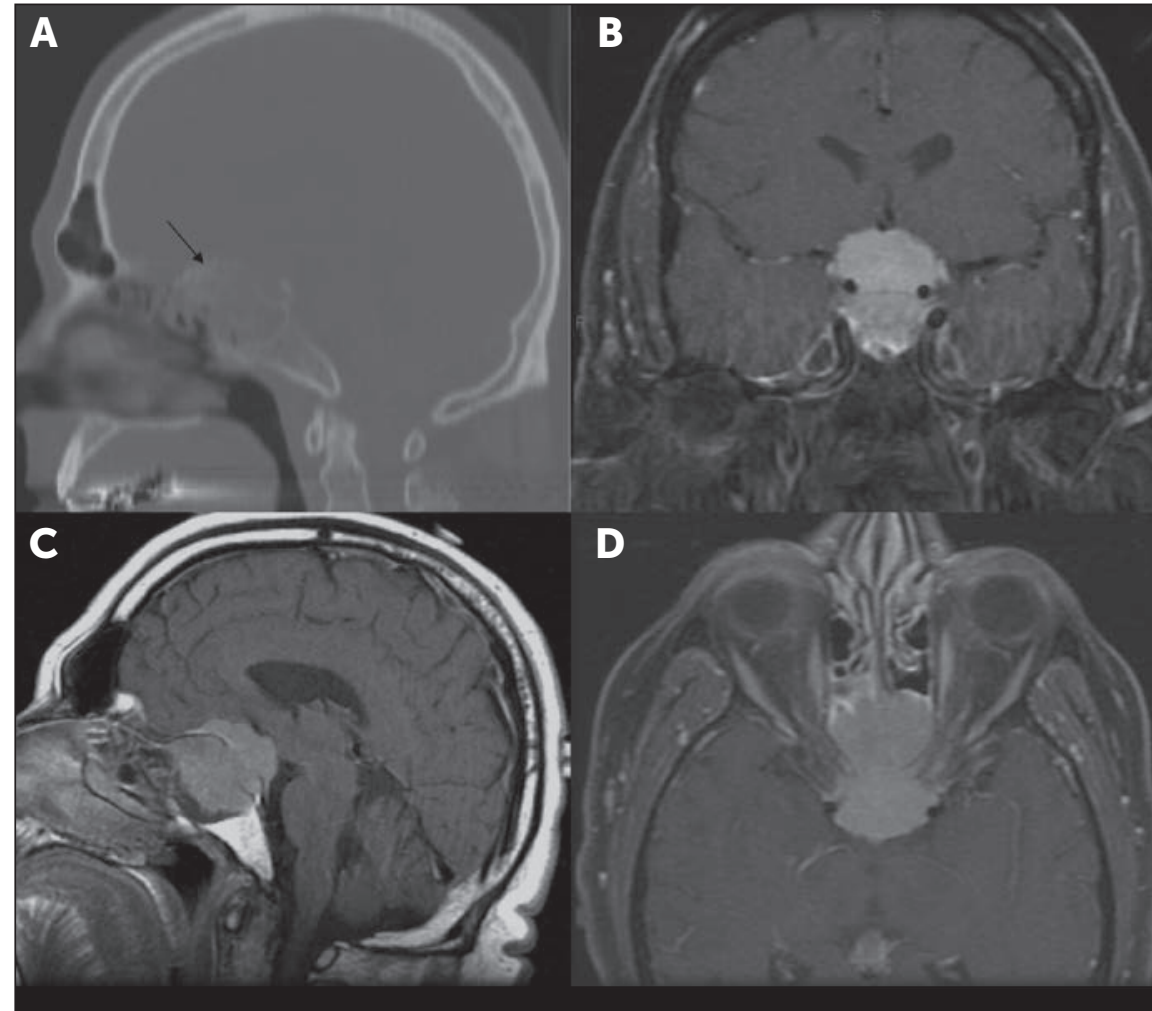

\section{Figure 3}

Preoperative imaging. A) Sagittal CT scan demonstrating extensive calcification of tumor (arrow). B) Coronal T1+contrast MRI demonstrating suprasellar extension of lesion and extension of tumor beyond the lateral margin of the cavernous carotid arteries. C) Sagittal and D) Axial T1+contrast MRI demonstrating invasion of the sphenoid sinus.

an endovascular approach (Figure 5B). One week after left ICA occlusion, the patient developed symptoms of left

\section{Learning point \#2:}

If a carotid injury is suspected, close post-operative assessment is necessary:

\section{Keep Looking!}

hemisphere hypoperfusion that became refractory to medical intervention with fluids and vasopressors. CTA confirmed the suspicion of diminished collateral vascular supply (Figure 6A). Thus, the decision was made to perform an external-to-internal carotid artery bypass (Figure 6B).
On immediate postoperative exam, the patient exhibited no residual weakness. The residual meningioma was subsequently treated with fractionated stereotactic radiotherapy and the patient remains stable for over five years since initial surgery.

\section{CONCLUDING KEY POINTS}

1. Endonasal anatomical and technical expertise is necessary to avoid and manage vascular injuries

2. Cavernous sinus meningiomas may not have a plane separating them from the ICA

3. If ICA injury suspected, keep looking!

4. ICA pseudo-aneurysms are best treated by vessel occlusion and early bypass when indicated 

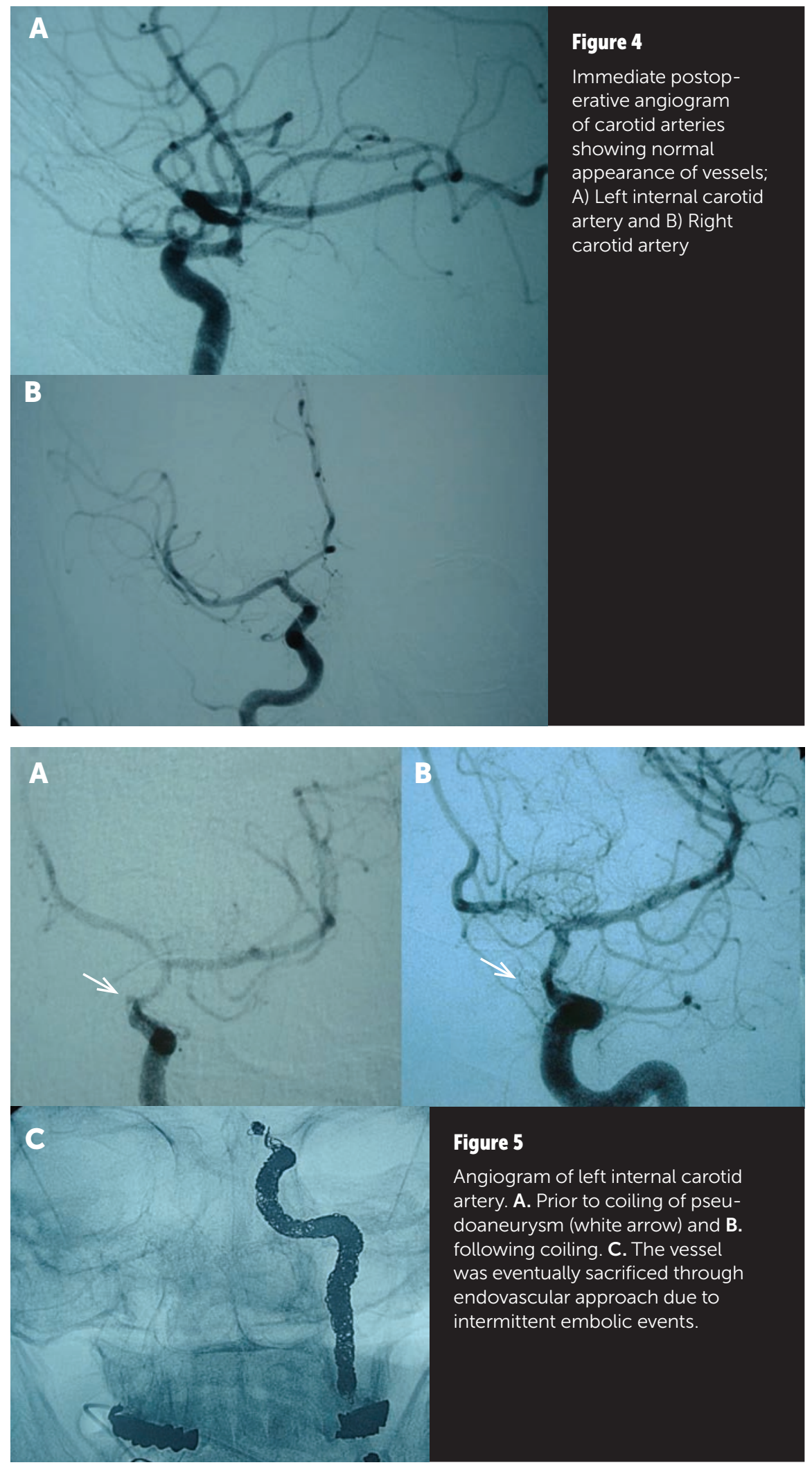

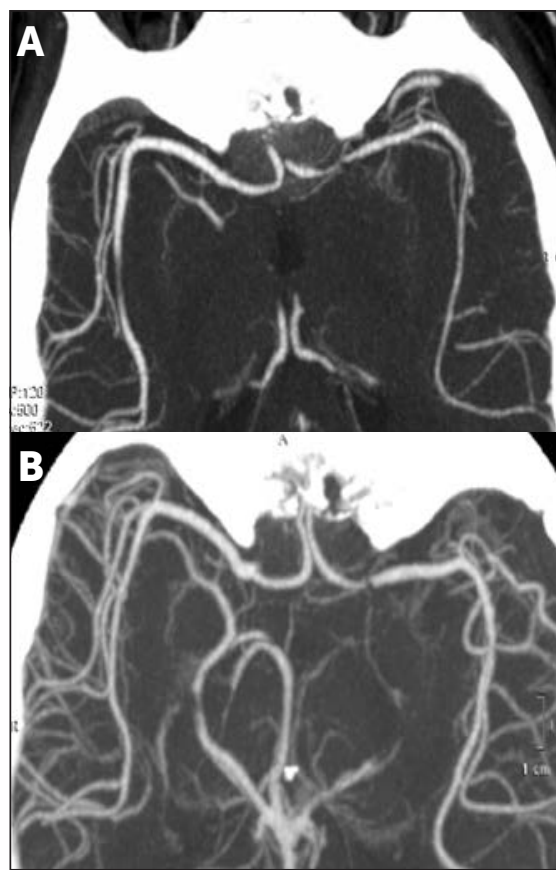

\section{Figure 6}

Axial CTA of vascular supply to cerebral hemispheres in $\mathbf{A}$. preoperative and $\mathbf{B}$. postoperative settings.

\section{REFERENCES}

1. Verillaud, B., et al., Mucocele after transnasal endoscopic repair of traumatic anterior skull base fistula in children. Int $\mathrm{J}$ Pediatr Otorhinolaryngol, 2011. 75(9): p. 1137-42.

2. Cavallo, L.M., et al., Endoscopic endonasal transsphenoidal surgery. Before scrubbing in: tips and tricks. Surg Neurol, 2007. 67(4): p. 342-7.

3. Cavallo, L.M., et al., Endoscopic endonasal surgery of the midline skull base: anatomical study and clinical considerations. Neurosurg Focus, 2005. 19(1): p. E2.

4. Koutourousiou, M., et al., Endoscopic endonasal approach for resection of cranial base chordomas: outcomes and learning curve. Neurosurgery, 2012. 71(3): p. 614-24; discussion 624-5.

5. Thirumala, P.D., et al., Somatosensory evoked potential monitoring during endoscopic endonasal approach to skull base surgery: analysis of observed changes. Neurosurgery, 2011. 69(1 Suppl Operative): p. ons64-76; discussion ons76.

6. Gardner, P.A., et al., Carotid artery injury during endoscopic endonasal skull base surgery: incidence and outcomes. Neurosurgery, 2013. 73(2 Suppl Operative): p. ons261-9; discussion ons269-70. 
7. Dusick, J.R., et al., Avoidance of carotid artery injuries in transsphenoidal surgery with the Doppler probe and micro-hook blades. Neurosurgery, 2007. 60(4 Suppl 2): p. 322-8 discussion 328-9.

8. Raithatha, R., et al., Endoscopic endonasal approaches to the cavernous sinus. Int Forum Allergy Rhinol, 2012. 2(1): p. 9-15

9. Kassam, A.B., et al., Endoscopic endonasal skull base surgery: analysis of complications in the authors' initial 800 patients. J Neurosurg, 2011. 114(6): p. 1544-68.

10. Frank, G., et al., The endoscopic transnasal transsphenoidal approach for the treatment of cranial base chordomas and chondrosarcomas. Neurosurgery, 2006. 59(1 Suppl 1): p. ONS50-7; discussion ONS50-7.

11. Stippler, M., et al., Endoscopic endonasal approach for clival chordomas. Neurosurgery, 2009. 64(2): p. 268-77 discussion 277-8

12. Caruso, R.D., et al., Craniocervical junction venous anatomy on enhanced MR images: the suboccipital cavernous sinus. AJNR Am J Neuroradiol, 1999. 20(6): p. 1127-31.
13. Fujii, K., S.M. Chambers, and A.L. Rhoton, Jr. Neurovascular relationships of the sphenoid sinus. A microsurgical study. J Neurosurg, 1979. 50(1): p. 31-9.

14. Renn, W.H. and A.L. Rhoton, Jr. Microsurgical anatomy of the sellar region. J Neurosurg, 1975. 43(3): p. 288-98.

15. Hamid, O., et al., Anatomic Variations of the Sphenoid Sinus and Their Impact on Transsphenoid Pituitary Surgery. Skull Base, 2008. 18(1): p. 9-15

16. Reddy, K., et al., False aneurysm of the cavernous carotid artery: a complication of transsphenoidal surgery. Surg Neurol, 1990. 33(2): p. 142-5.

17. Rhoton, A.L., Jr., The sellar region. Neurosurgery, 2002. 51(4 Suppl): p. S335-74.

18. Valentine, R. and P.J. Wormald, Carotid artery injury after endonasal surgery. Otolaryngol Clin North Am, 2011. 44(5): p. 1059-79.

19. Valentine, R., et al., The efficacy of hemostatic techniques in the sheep model of carotid artery injury. Int Forum Allergy Rhinol, 2011. 1(2): p. 118-22.
20. Inamasu, J. and B.H. Guiot, latrogenic carotid artery injury in neurosurgery. Neurosurg Rev, 2005. 28(4): p. 239-47; discussion 248

21. Fukushima, T. and J.C. Maroon, Repair of carotid artery perforations during transsphenoidal surgery. Surg Neurol, 1998. 50(2): p. 174-7

22. Wilson, C.B. and L.C. Dempsey, Transsphenoidal microsurgical removal of 250 pituitary adenomas. J Neurosurg, 1978 48(1): p. 13-22.

23. Kadyrov, N.A., et al., Endovascular treatment of an internal carotid artery pseudoaneurysm following transsphenoidal surgery. Case report. J Neurosurg, 2002. 96(3): p. 624-7.

24. Benoit, B.G. and G. Wortzman, Traumatic cerebral aneurysms. Clinical features and natural history. J Neurol Neurosurg Psychiatry, 1973. 36(1): p. 127-38.

25. Higashida, R.T., et al., Interventional neurovascular treatment of traumatic carotid and vertebral artery lesions: results in 234 cases. AJR Am J Roentgenol, 1989. 153(3): p. 577-82.

26. Geremia, G., M. Haklin, and L. Brennecke, Embolization of experimentally created aneurysms with intravascular stent devices. AJNR Am J Neuroradiol, 1994. 15(7): p. 1223-3

\section{ENDDСHICへБロ}

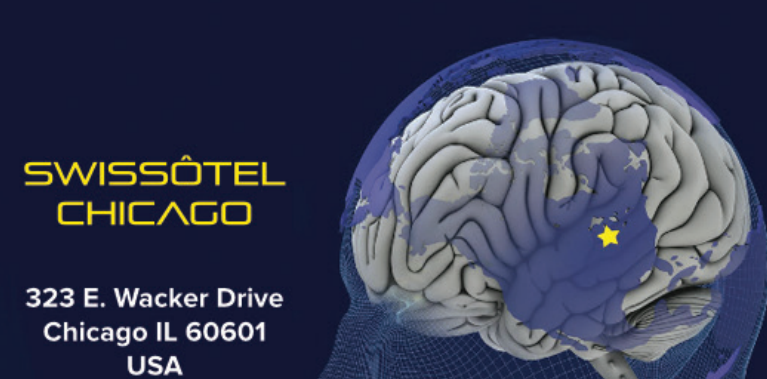

MAY

$15-18$ टำ

Jefferson James J. Evans, MD Marc R. Rosen, MD

The Ohio State University Ricardo L. Carrau, MD, FACS Daniel M. Prevedello, MD

Weill Cornell Brain and Spine Center Vijay Anand, MD, FACS Theordore H. Schwartz, MD, FACS

Aurora St. Luke's Medical Center Amin B. Kassam, MD

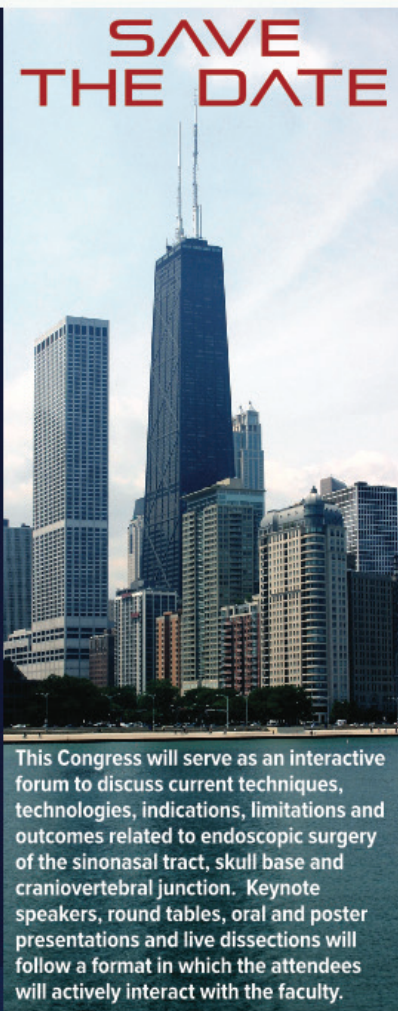

